\title{
Heterogeneity among 16S-23S rRNA intergenic spacers of species within the 'Streptococcus milleri group"
}

\author{
R. A. Whiley, ${ }^{1}$ B. Duke, ${ }^{2}$ J. M. Hardie' ${ }^{1}$ and L. M. C. Hall ${ }^{2}$ \\ Author for correspondence: R. A. Whiley. Tel: +44171 3777000 ext. 3219. Fax: +44171 3777677. \\ e-mail: R.Whiley@lhmc.ac.uk
}

Departments of Oral Microbiology ${ }^{1}$ and Medical Microbiology'2, The London Hospital Medical College, Turner Street, London E1 2AD, UK

\begin{abstract}
The 16S-235 rRNA intergenic spacer has been suggested as a suitable region of the bacterial genome from which to derive useful taxonomic information, particularly with regard to identification at the species level. To investigate this approach as an aid to the identification of the three species comprising the 'Streptococcus milleri group' (SMG), the spacers of isolates of Streptococcus intermedius, Streptococcus anginosus and Streptococcus constellatus were amplified by PCR and length polymorphisms determined by agarose gel electrophoresis. Phenotypically atypical isolates which had been identified presumptively as belonging to these three species were also included. Spacers from two representatives of each spacer length found within the three SMG species were sequenced. 16S-23S rRNA intergenic spacer length polymorphisms allowed discrimination between S. anginosus (350 bp or 450 bp amplification product) and S. constellatus ( 380 bp amplification product), species that are difficult to differentiate phenotypically. S. intermedius (330 bp or 450 bp amplification product) and S. anginosus (350 bp or 450 bp amplification product) were not reliably distinguished by this method but are phenotypically distinct. Sequencing data demonstrated that the spacers had a central region of highly variable length flanked by conserved regions which included a single tRNA $A_{\text {Ala }}$ gene. Polymorphism in the length of the 16S-235 spacer determined by PCR provides a rapid and useful adjunct to strain identification for S. anginosus and S. constellatus, which are not readily differentiated phenotypically.
\end{abstract}

Keywords: Streptococcus intermedius, Streptococcus anginosus, Streptococcus constellatus, 16S-23S intergenic rRNA spacer, length polymorphism

\section{INTRODUCTION}

Comparative sequence analysis of small subunit $\mathrm{rRNA}$ genes is currently used to determine phylogenetic relationships between both closely and distantly related bacteria (Woese, 1987) and to derive species-specific DNA probes for strain identification (Stahl \& Amann, 1991; Greisen $e t$ al., 1994). Within the rRNA operon (rrn), the intergenic spacer separating the $16 \mathrm{~S}$ and $23 \mathrm{~S}$ rRNA genes has been suggested as a candidate region from which DNA probes

Abbreviations: SMG, 'Streptococcus milleri group'; T, type strain.

The GenBank accession numbers for the nucleotide sequences reported in this paper are: L36931 [S.ang 450 (strain NCTC 10713')]; L36932 [S.ang 350 (isolate Q4039)]; L36933 [S.Con L $_{380}$ (strain NCDO 2226')]; L36934 [S.int $_{330}$ (strain NCDO 2227')]; L36935 [S.int ${ }_{450}$ (isolate HW12)]. for identification and strain typing may be derived (Barry et al., 1991; Uemori et al., 1992; Kostman et al., 1992; Gurtler, 1993). This region is involved in the processing of pre-RNA (Young \& Steitz, 1978) and may contain coding sequences for tRNA (Morgan et al., 1977; Young et al., 1979; Bacot \& Reeves, 1991) but is otherwise considered to be largely non-functional, under minimal selective pressure and therefore likely to contain sequence variations from which taxonomically useful information might be obtained (Barry et al., 1991). Indeed, sequence divergence between different species within a genus has already been reported (Barry et al., 1991; Frothingham \& Wilson, 1994; Uemori et al., 1992). Conserved regions within the $16 \mathrm{~S}$ and $23 \mathrm{~S}$ genes can be used as targets for primers to amplify the intergenic spacer by PCR (i) in order to determine size polymorphisms on agarose gels 
for use as species specific markers or (ii) for direct sequencing in order to determine the presence of oligonucleotide signatures suitable for primers to be used in a PCR-based identification approach (Barry et al., 1991; McLaughlin et al., 1993).

Streptococcus anginosus, $S$. constellatus and S. intermedius (often collectively referred to as the 'Streptococcus milleri group': SMG) (Whiley \& Beighton, 1991) are common inhabitants of the human oral cavity (Whiley et al., 1993) and are of clinical interest due to an association with oral abscesses and more serious purulent infections that may involve the major organs of the body (Gossling, 1988; Whiley et al., 1992). Bentley et al. (1991) demonstrated by $16 \mathrm{~S}$ rRNA sequence analysis that these three species are phylogenetically distinct taxa, grouped together and possessing a common line of descent. However, routine identification of these streptococci is currently only possible using a biochemical scheme that includes fluorogenic substrates for detecting preformed enzymes together with traditional bacteriological tests (Whiley et al., 1990). This approach is particularly suitable for identifying isolates of $S$. intermedius, a phenotypically distinct species when compared with $S$. anginosus and $S$. constellatus. As noted by previous authors (Kilpper-Balz et al., 1984) the latter two species are less readily distinguished from each other by phenotypic tests and present much more of a potential problem to the diagnostic microbiologist. At the present time discrimination between, and therefore identification of, S. anginosus and $S$. constellatus, although improved, would be greatly facilitated by a simple DNA-based test.

The aim of this study was to investigate the presence and basis of length polymorphisms within the $16 \mathrm{~S}-23 \mathrm{~S}$ rRNA intergenic spacers of $S$. anginosus, $S$. constellatus and $S$. intermedius and to determine whether exploitation of this region of the genome represents a suitable alternative or adjunct to the identification of SMG species by phenotypic testing.

\section{METHODS}

Bacterial strains. A total of 65 streptococci belonging to the SMG were examined: these had been identified previously as $S$. intermedius (21 isolates), $S$. constellatus (22 isolates) or $S$. anginosus (22 isolates) on the basis of whole genomic DNA-DNA hybridization (Whiley \& Hardie, 1989), cluster analysis or using the biochemical scheme of Whiley et al. (1990). The strains examined included the type strains NCTC $10713^{\mathrm{T}}$ (S. anginosus), NCDO $2226^{\mathrm{T}}$ (S. constellatus) and NCDO $2227^{\mathrm{T}}$ (S. intermedius). The biochemical profiles (biotypes) of the reference strains and clinical isolates examined in this study are shown in Table 1. Six of the $S$. anginosus isolates possessed a broader fermentation capability than most in being able to produce acid from mannitol $(\operatorname{mann}+)$ and raffinose $(\mathrm{raff}+)$. Isolates with the latter phenotype have been described before and are frequently isolated from the urogenital tract (Ruoff \& Kunz, 1982). Also included amongst the above were two 'atypical-S. constellatus' isolates characterized by an inability to hydrolyse aesculin or arginine (biotype $\mathrm{c} 11$, isolate $\mathrm{F} 436$ ) or in not producing detectable levels of $\alpha$-glucosidase or hyaluronidase (biotype c10, isolate FW73), four isolates presumptively identified as $S$. intermedius which did not produce detectable levels of sialidase (sial-) (biotype i5, isolate 3206393 ; biotype $i 6$, isolate 3206692 ; biotype i3, isolates 3209432 and I782) and two isolates of $S$. anginosus in which hyaluronidase activity was detected (biotype a9, isolate AGP37W and biotype i10, isolate MS101).

All cultures were incubated at $37^{\circ} \mathrm{C}$ in an anaerobic atmosphere of $\mathrm{H}_{2} / \mathrm{CO}_{2} / \mathrm{N}_{2}$ (20:10:70, by vol.). Cultivation was carried out in Streptococcus Sugar Base broth (SSB) containing 2\% (w/v) proteose peptone (Oxoid), $0.5 \%(\mathrm{w} / \mathrm{v})$ yeast extract (Difco), $0.5 \%$ (w/v) $\mathrm{NaCl}, 0 \cdot 1 \%$ (w/v) $\mathrm{Na}_{2} \mathrm{HPO}_{4}, \mathrm{pH} 7 \cdot 6$, supplemented with $0.5 \%(\mathrm{w} / \mathrm{v})$ glucose and $0.25 \%$ (w/v) $\mathrm{NaHCO}_{3}$. Cells were grown in $3 \mathrm{ml}$ cultures to late exponential phase (assessed visually) and harvested by centrifugation. Cells were washed and then resuspended in $0.1 \mathrm{ml}$ TE buffer $(10 \mathrm{mM}$ Tris $/ \mathrm{HCl}, 1 \mathrm{mM}$ EDTA, $\mathrm{pH} 8 \cdot 0$ ). Lysozyme was added to a final concentration of $5 \mathrm{mg} \mathrm{ml}^{-1}$, and the mixture was incubated at $37^{\circ} \mathrm{C}$ for $30 \mathrm{~min}$. The cells were then lysed by adding $0.5 \mathrm{ml}$ GES buffer ( $5 \mathrm{M}$ guanidium thiocyanate, $0 \cdot 1 \mathrm{M}$ EDTA, $\mathrm{pH} 8 \cdot 0$, $0.5 \%, \mathrm{w} / \mathrm{v}, N$-laurylsarcosine) and incubated at room temperature for at least $10 \mathrm{~min}$. After extraction with an equal volume of chloroform/isoamyl alcohol (24:1), the DNA was precipitated with 0.54 vols 2 -propanol, resuspended, then precipitated with ethanol and finally resuspended in $0.1-0.2 \mathrm{ml}$ TE buffer.

PCR. PCR was performed with GeneAmp PCR core reagents, $2.5 \mathrm{mM} \mathrm{MgCl}_{2}$, and AmpliTaq polymerase (Perkin Elmer Cetus). Primers used for determining size polymorphisms were A : 5'-GAAGTCGTAACAAGGTA(AG)CCGT-3' and B: $5^{\prime}$ TGCCAAGGCATCCACC-3' (nucleotides in parentheses are degenerate nucleotide positions). The $5^{\prime}$-end of primer $A$ is located at position 1491 of the $16 \mathrm{~S}$ rRNA gene and the $5^{\prime}$-end of primer B 23 bp downstream from the $5^{\prime}$-end of the $23 \mathrm{~S}$ rRNA gene ( $E$. coli numbering). Reaction conditions were $95^{\circ} \mathrm{C}$ for $1 \mathrm{~min}, 55^{\circ} \mathrm{C}$ for $1 \mathrm{~min}, 72^{\circ} \mathrm{C}$ for $1 \mathrm{~min}$, with 30 cycles on a Hybaid thermal reactor with plate control. Primer concentration was $1 \mu \mathrm{g} \mathrm{ml}^{-1}$. PCR amplifications were analysed on $1.5 \%$ $(\mathrm{w} / \mathrm{v})$ agarose gels.

DNA-DNA reassociation. This was carried out by the S1nuclease method of Crosa et al. (1973) using reference $\left[{ }^{3} \mathrm{H}\right] \mathrm{DNA}$ from type strains NCDO $2226^{\mathrm{T}}$ (S. constellatus), NCDO $2227^{\mathrm{T}}$ (S. intermedius) and NCTC $10713^{\mathrm{T}}$ (S. anginosus) as described previously (Whiley \& Hardie, 1989). DNA purification for these experiments was by the method of Garvie (1976). Reassociation experiments were carried out under stringent $\left(75^{\circ} \mathrm{C}\right)$ conditions and all hybridizations were performed in triplicate. Controls included a homologous reassociation as a positive $(100 \%)$ control and calf thymus DNA as a negative $(0 \%)$ control. For each test DNA the degree of sequence homology was expressed as a percentage of the homologous control after correction for self reassociation in the negative control.

DNA sequencing. PCR products, generated with primers $C: 5^{\prime}-$ CTTGCACACACCGCCCGTCA-3' and D: 5'-CCACGTCCTTC(AT)'TCG(CG)CT-3', [5' biotin] (nucleotides in parentheses are degenerate nucleotide positions) under the same conditions as described earlier, were purified and the strands separated using paramagnetic beads conjugated with Streptavidin (Dynabeads M-280 Streptavidin, Dynal) according to the manufacturer's instructions. 'The $5^{\prime}$-end of primer $C$ is located at position 1389 of the $16 \mathrm{~S}$ rRNA gene and the $5^{\prime}$-end of primer $\mathrm{D}$ at position 44 downstream of the $5^{\prime}$-end of the $23 \mathrm{~S}$ rRNA gene ( $E$. coli numbering). The biotin-labelled strand and the unlabelled strand were purified separately and used as templates for sequencing using primers $\mathrm{A}$ and $\mathrm{B}$, respectively. Sequencing was performed by chain termination using a Sequenase version $2.0 \mathrm{kit}$ and protocol (USB). Sequences were 
Table 1. Biotypes examined

Abbreviations: Amyg, amygdalin; Lac, lactose; Mann, mannitol; Raff, raffinose; Aesc, aesculin; Arg, arginine; $\beta$-DFuc, $\beta$-D-fucosidase; $\beta$-NAGal, $\beta$ - $N$-acetylgalactosaminidase; Sial, sialidase; $\beta$-NAGlu, $\beta$ - $N$-acetylglucosaminidase; $\beta$-Gal, $\beta$-galactosidase; $\alpha$-Gal, $\alpha$-galactosidase; $\alpha$-Glu, $\alpha$-glucosidase; $\beta$-Glu, $\beta$-glucosidase; Hyal, hyaluronidase. $n$, Number of strains/isolates.

\begin{tabular}{|c|c|c|c|c|c|c|c|c|c|c|c|c|c|c|c|c|}
\hline \multirow{3}{*}{$\begin{array}{l}\text { Species and } \\
\text { (biotypes) }\end{array}$} & \multirow[t]{3}{*}{$n=$} & \multicolumn{4}{|c|}{ Acid from: } & \multirow{2}{*}{\multicolumn{2}{|c|}{$\begin{array}{c}\text { Hydrolysis } \\
\text { of: }\end{array}$}} & \multicolumn{9}{|c|}{ Production of: } \\
\hline & & \multirow[t]{2}{*}{ Amyg } & \multirow[t]{2}{*}{ Lac } & \multirow[t]{2}{*}{ Mann } & \multirow[t]{2}{*}{ Raff } & & & \multirow{2}{*}{$\begin{array}{c}\beta- \\
\text { DFuc I }\end{array}$} & \multirow{2}{*}{$\begin{array}{c}\beta- \\
\text { NAGal }\end{array}$} & \multirow{2}{*}{ Sial } & \multirow{2}{*}{$\begin{array}{c}\beta- \\
\text { NAGlu }\end{array}$} & \multirow{2}{*}{$\beta$-Gal } & \multirow[t]{2}{*}{$\alpha-G a l$} & \multirow[t]{2}{*}{$\alpha$-Glu } & \multirow[t]{2}{*}{$\beta$-Glu } & \multirow[t]{2}{*}{ Hyal } \\
\hline & & & & & & Aesc & Arg & & & & & & & & & \\
\hline \multicolumn{17}{|c|}{ S. intermedius } \\
\hline$($ i1)* & 13 & + & + & - & - & + & + & + & + & + & + & + & - & + & + & + \\
\hline (i2) & 3 & - & + & - & - & + & + & + & + & + & + & + & - & + & - & + \\
\hline (i3) & 2 & + & + & - & + & + & + & + & + & - & + & + & - & + & + & + \\
\hline (i4) & 1 & + & + & - & - & + & + & + & + & + & + & + & - & + & - & + \\
\hline (i5) & 1 & - & + & - & - & + & - & + & + & - & + & + & - & + & + & + \\
\hline (i6) & 1 & + & + & - & - & + & + & + & + & - & + & + & - & + & + & + \\
\hline \multicolumn{17}{|c|}{ S. constellatus } \\
\hline (c1) & 4 & - & - & - & - & + & + & - & - & - & - & - & - & + & - & + \\
\hline (c2) & 3 & - & - & - & - & - & + & - & - & - & - & - & - & + & - & + \\
\hline (c3) & 3 & + & - & - & - & + & + & - & - & - & - & - & - & + & - & + \\
\hline (c4) & 4 & + & + & - & - & + & + & - & - & - & - & - & - & + & - & + \\
\hline (c5)† & 2 & - & + & - & - & + & + & - & - & - & - & - & - & + & - & + \\
\hline (c6) & 1 & - & + & + & - & + & + & - & - & - & - & - & - & + & - & + \\
\hline (c7) & 1 & - & - & - & - & + & + & - & - & - & - & - & - & - & - & + \\
\hline (c8) & 1 & - & + & - & - & + & + & - & - & - & - & - & - & - & - & + \\
\hline (c9) & 1 & - & + & - & - & - & + & - & - & + & - & - & - & + & - & + \\
\hline (c10) & 1 & - & + & - & - & + & + & - & - & - & - & - & - & - & - & - \\
\hline (c11) & 1 & - & - & - & - & - & - & - & - & - & - & - & + & + & - & + \\
\hline \multicolumn{17}{|l|}{ S. anginosus } \\
\hline (a1) & 10 & + & + & - & - & + & + & - & - & - & - & - & - & - & + & - \\
\hline (a2) & 2 & + & + & - & - & + & + & - & - & - & - & - & - & - & - & - \\
\hline (a3) & 2 & + & + & + & + & + & + & - & - & - & - & - & - & + & + & - \\
\hline (a4) & 2 & + & + & + & + & + & + & - & - & - & - & + & + & + & + & - \\
\hline (a5) & 1 & + & + & + & + & + & + & - & - & - & - & + & - & + & + & - \\
\hline (a6)‡ & 1 & + & + & - & + & + & + & - & - & - & - & - & - & - & + & - \\
\hline (a7) & 1 & + & + & + & + & + & - & - & - & - & - & - & - & + & + & - \\
\hline (a8) & 1 & + & - & - & - & + & + & - & - & - & - & - & + & - & + & - \\
\hline (a9) & 1 & + & + & - & - & + & + & - & - & - & - & - & - & + & + & + \\
\hline (a10) & 1 & + & + & - & - & + & + & - & - & - & - & + & - & + & + & + \\
\hline
\end{tabular}

* Biotype includes NCDO $2227^{\mathrm{T}}$.

† Biotype includes NCDO $2226^{\mathrm{T}}$.

$\ddagger$ Biotype includes NCDO $10713^{\mathrm{T}}$.

read on a sonic digitizer and processed with PC/gene software (Intelligenetics). Spacers from two representative strains of each spacer length found within the three species were sequenced.

\section{RESULTS}

\section{Size polymorphisms within the 16S-23S rRNA spacer regions}

All PCR amplifications carried out using primers A and B resulted in the detection of single bands on agarose gels. Fragment sizes determined by comparison against molecular size markers (123 bp ladder, Gibco BRL) are summarized in Table 2. Representative examples of the 16S-23S amplification products are shown in Fig. 1. Ambiguous nucleotide positions on the sequencing gels that could reflect heterogeneity between different copies of the spacer were not observed.

Twenty isolates previously identified as $S$. constellatus yielded a $380 \mathrm{bp}$ PCR product. Two isolates designated as 'atypical S. constellatus' (FW73 biotype c10 and F436 biotype c11) differed by giving $450 \mathrm{bp}$ and 300 bp PCR products, respectively. All 13 mann-, raff-, hyal(biotypes $\mathrm{a} 1, \mathrm{a} 2, \mathrm{a} 8$ ) isolates of $S$. anginosus examined together with the type strain NCTC $10713^{\mathbf{T}}$ (biotype a6) 
Table 2. Size polymorphisms of the PCR products within SMG species, determined using primers $A$ and $B$

\begin{tabular}{|c|c|c|c|c|}
\hline Species & Biotypes & $\begin{array}{l}\text { Size of PCR } \\
\text { product (bp) }\end{array}$ & $\begin{array}{c}\text { No. examined } \\
(n)\end{array}$ & $\begin{array}{c}\text { Spacer } \\
\text { designation }\end{array}$ \\
\hline 'Atypical-S. constellatus' (FW73) & $\mathrm{c} 10$ & 450 & 1 & \\
\hline 'Atypical-S. constellatus' (F436) & c11 & 300 & 1 & \\
\hline S. anginosus & $a 1, a 2, a 6, a 8$ & 450 & 14 & S.ang ${ }_{450}$ \\
\hline S. intermedius & $\mathrm{i} 1, \mathrm{i} 2, \mathrm{i} 4$ & 450 & 10 & S.int 450 \\
\hline S. intermedius & i1, i2 & 330 & 7 & S.int $_{330}$ \\
\hline 'Atypical-S. intermedius' (1782, 3206393, 3206692) & $\mathrm{i} 3, \mathrm{i} 5, \mathrm{i} 6$ & 380 & 3 & \\
\hline 'Atypical-S. intermedius' (3209432) & i3 & 330 & 1 & \\
\hline
\end{tabular}

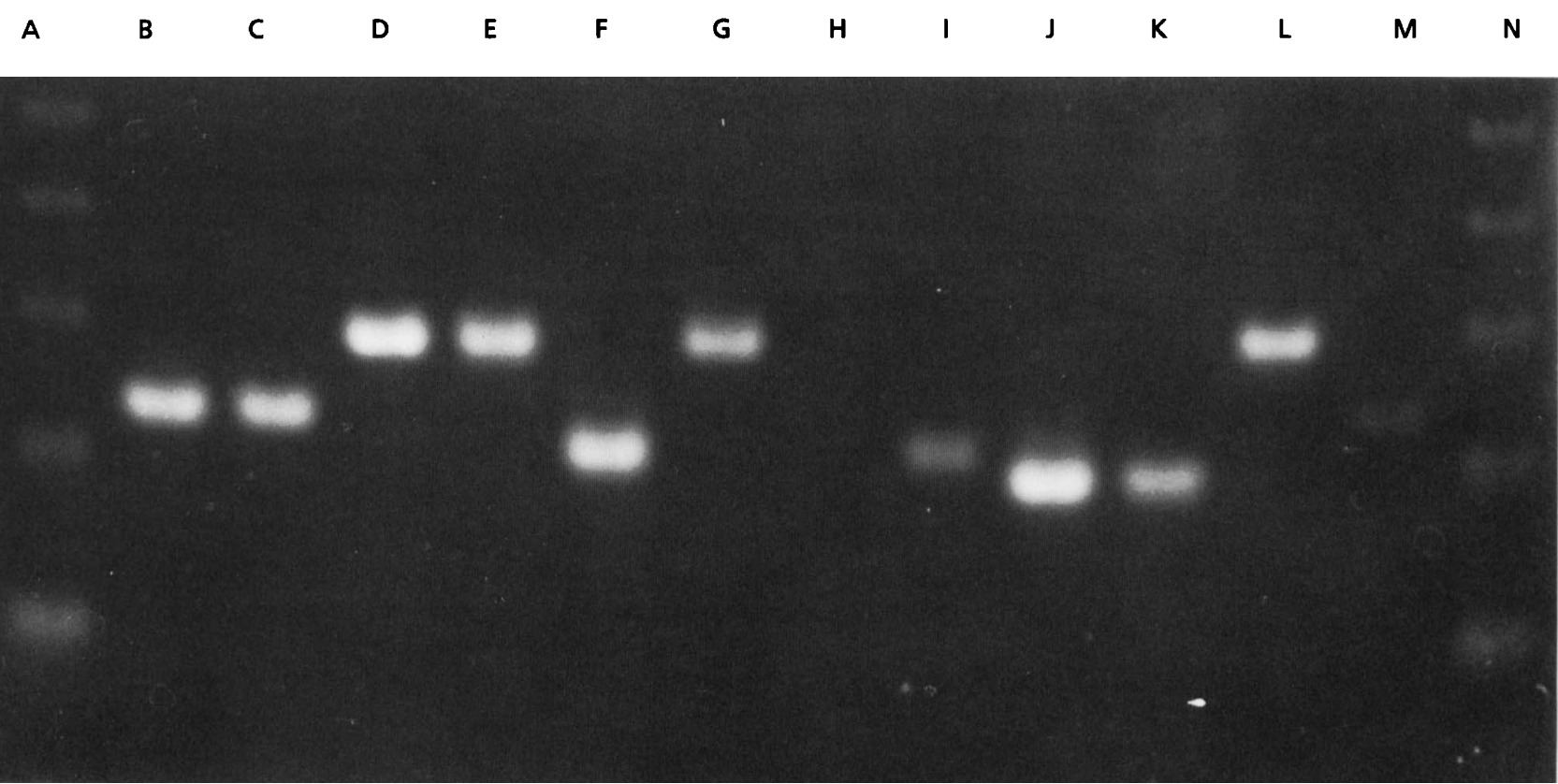

Fig. 1. PCR amplification products. Lanes: $B$ and $C, S$. constellatus (S.con $\left.{ }_{380}\right) ; E$ and G, S. anginosus $(S$.ang ano $) ; F$ and I, S. anginosus (S.ang $\left.{ }_{350}\right)$; J and K, S. intermedius (S.int I30 $_{0}$ ); L, S. intermedius (S.int 450 ); D, phenotypically atypical isolate FW73 (biotype (11); M, phenotypically atypical isolate 3206393 (biotype i5); H, negative control lane; A and N, molecular size markers of $246,369,492,615$ and 738 bp (123 bp ladder, Gibco BRL).

were characterized by a 450 bp PCR product and all six mann + , raff + , hyal - (biotypes a3, a4, a 7 ) isolates of this species tested differed from the former by the production of a shorter, $350 \mathrm{bp}$ fragment. Isolates identified presumptively as hyaluronidase-producing $S$. anginosus (AGP37-W and MS101, biotypes a9 and a10) both gave a $380 \mathrm{bp}$ PCR product. Isolates of $S$. intermedius were divided into two groups yielding either a longer, $450 \mathrm{bp}$ $(n=10)$, or shorter, $330 \mathrm{bp}(n=8)$, PCR product, respectively. In addition, three sial- isolates that had been presumptively assigned to $S$. intermedius (3206393 biotype i5 ; 3206692 biotype i6; and 1782 biotype i3) were distinguished from other $S$. intermedius isolates by the production of a $380 \mathrm{bp}$ band. The fourth sial - isolate examined (3209432, biotype i3) was included in the $330 \mathrm{bp}$ group.

\section{DNA-DNA reassociations}

'Atypical-S. constellatus' isolates ( $\mathrm{F} 436$ and FW73), '(sial-) S. intermedius' isolates (3206393 and I782) together with hyaluronidase-producing $S$. anginosus isolates AGP37-W and MS101 were examined by DNA-DNA reassociation. Of these, only 1782 could be assigned with confidence to one or other of the SMG species; $88 \%$ similarity was shared with S. intermedius type strain NCDO $2227^{\mathrm{T}}$ compared to $30 \%$ and $42 \%$ with type strains NCTC $10713^{\mathrm{T}}$ (S. anginosus) and NCDO $2226^{\mathrm{T}}$ 
Table 3. DNA-DNA reassociations of atypical isolates

Numbers show the range for each set of replicates with the mean in parentheses.

\begin{tabular}{|c|c|c|c|}
\hline \multirow[t]{2}{*}{ Unlabelled DNA from: } & \multicolumn{3}{|c|}{$\begin{array}{l}\text { Percentage reassociation with } \\
\text { reference }\left[{ }^{3} \mathrm{H}\right] \mathrm{DNA} \text { from: }\end{array}$} \\
\hline & $\begin{array}{l}\text { NCTC } \\
10713^{\mathrm{T}}\end{array}$ & $\begin{array}{c}\text { NCDO } \\
2226^{\mathrm{T}}\end{array}$ & $\begin{array}{c}\text { NCDO } \\
2227^{\mathrm{T}}\end{array}$ \\
\hline NCTC $10713^{\mathrm{T}}$ & 100 & $\begin{array}{c}34-39 \\
(37)\end{array}$ & $\begin{array}{c}46-58 \\
(50)\end{array}$ \\
\hline NCDO $2226^{\mathrm{T}}$ & $\begin{array}{c}28-33 \\
(30)\end{array}$ & 100 & $\begin{array}{c}12-33 \\
(21)\end{array}$ \\
\hline NCDO $2227^{\mathrm{T}}$ & $\begin{array}{c}36-46 \\
(39)\end{array}$ & $\begin{array}{c}43-55 \\
(48)\end{array}$ & 100 \\
\hline \multicolumn{4}{|l|}{ Atypical-S. constellatus } \\
\hline F436 & $\begin{array}{c}36-41 \\
(38)\end{array}$ & $\begin{array}{c}5-8 \\
(7)\end{array}$ & $\begin{array}{c}26-42 \\
(33)\end{array}$ \\
\hline FW73 & $\begin{array}{c}45-52 \\
(47)\end{array}$ & $\begin{array}{c}18-26 \\
(21)\end{array}$ & $\begin{array}{c}26-28 \\
(27)\end{array}$ \\
\hline \multicolumn{4}{|l|}{ Atypical-S. anginosus } \\
\hline AGP37-W & $\begin{array}{l}9-7 \\
(8)\end{array}$ & $\begin{array}{l}1-3 \\
(2)\end{array}$ & $\begin{array}{l}8-20 \\
(13)\end{array}$ \\
\hline MS101 & $\begin{array}{c}20-28 \\
(24)\end{array}$ & $\begin{array}{c}41-48 \\
(45)\end{array}$ & $\begin{array}{c}43-48 \\
(46)\end{array}$ \\
\hline \multicolumn{4}{|l|}{ Atypical-S. intermedius } \\
\hline $\mathrm{I} 782$ & $\begin{array}{c}25-33 \\
(30)\end{array}$ & $\begin{array}{c}35-47 \\
(42)\end{array}$ & $\begin{array}{c}78-97 \\
(88)\end{array}$ \\
\hline 3206393 & $\begin{array}{c}33-39 \\
(36)\end{array}$ & $\begin{array}{c}34-42 \\
(39)\end{array}$ & $\begin{array}{c}44-54 \\
(48)\end{array}$ \\
\hline
\end{tabular}

(S. constellatus), respectively. None of the remaining isolates tested demonstrated sufficient similarity with these type strains to be assigned to a species, with all giving less than $60 \%$ DNA reassociation with the reference DNAs (Table 3). All of these isolates were subsequently re-examined by biochemical testing in order to check the original identifications and gave identical results to those obtained previously.

\section{DNA sequencing of 16S-235 spacer regions}

Sequencing of the 16S-23S spacers was carried out on two representatives for each size of PCR product obtained from all three species. Aligned sequences are shown in Fig. 2. The 16S-23S spacers were determined to be either $270 \mathrm{bp}$ (short) or 391/392 bp (long) in length for $S$. intermedius, $319 \mathrm{bp}$ for $S$. constellatus and either 388/391 bp (long) or $295 \mathrm{bp}$ (short) for $S$. anginosus. All sequences contained a single tRNA $A_{A l a}$ gene as described previously for $S$. pneumoniae (Bacot \& Reeves, 1991).

Intra-specific heterogeneity. No sequence heterogeneity was found in the short spacer of $S$. anginosus (isolates Q4039 and K481) or the short spacer of S. intermedius (strain NCDO $2227^{\mathrm{T}}$ and isolate 10a). Sequences of the two representative long $16 \mathrm{~S}-23 \mathrm{~S}$ spacers examined in S. intermedius (isolates HW12 and GN556) and in S. constellatus (strain NCDO $2226^{\mathrm{T}}$ and isolate UNS55) each had a single base difference, while the long spacer of $S$. anginosus exhibited a greater degree of genetic heterogeneity with differences at seven positions between NCTC $10713^{\text {T }}$ and SL15 (Fig. 2). The main difference between the long and short spacers of $S$. anginosus was the presence of a $97 \mathrm{bp}$ insertion/deletion at position 184 together with nine single base differences (Fig. 2). In contrast, the short and long spacers of $S$. intermedius were identical for the first $137 \mathrm{bp}$ and final $110 \mathrm{bp}$ but the overall difference in length was not accountable for by a single insertion/ deletion event as there was considerable sequence divergence in the central section of the spacer.

Inter-specific heterogeneity. All spacer variants from the three species share a high degree of sequence homology for the first $132 \mathrm{bp}$ and the last $101 \mathrm{bp}$ of their lengths. In the central region there is both sequence and length heterogeneity, precluding any useful calculation of percentage homology. However, the two spacers showing greatest similarity are the long variants of $S$. intermedius and $S$. anginosus with only ten mismatched bases and five bases deleted/inserted. The short spacers in these species are less similar to each other, with the long $S$. intermedius spacer having less sequence in common with the short $S$. intermedius spacer than it does with either $S$. anginosus spacer variant. The spacer sequence of $S$. constellatus is distinct from the sequences of both the other two species.

\section{DISCUSSION}

The results of this study demonstrate that the 16S-23S rRNA intergenic spacers within the SMG contain sufficient interspecific length polymorphisms and intraspecific conservation to serve as a valuable adjunct to biochemical testing for discriminating between $S$. anginosus and S. constellatus. This is especially useful in view of the close phenotypic similarity of these two species. In contrast, however, the presence of virtually identical long spacers in a large proportion of isolates of $S$. intermedius and $S$. anginosus shows that this approach is of little value in differentiating these two species compared to their relatively straightforward identification on the basis of phenotypic criteria. It is of interest that isolates of the same species have been shown here to possess spacers of different length although this has been reported previously for Pseudomonas cepacia (Kostman et al., 1992) and within species of Bacillus (Gottlieb \& Rudner, 1985). However, no evidence was obtained in the present study to suggest that there was heterogeneity between rRNA operons of a single isolate (intra-genomic heterogeneity in spacer length was observed previously within E. faecalis; Hall, 1994).

The potential use of $16 \mathrm{~S}-23 \mathrm{~S}$ spacer length determination for identification is further illustrated by the results obtained with phenotypically atypical isolates; the problem of identifying biochemically atypical isolates of $S$. anginosus and $S$. constellatus has been highlighted previously (Kilpper-Balz et al., 1984) and remains despite some improvement in the discrimination between these two 


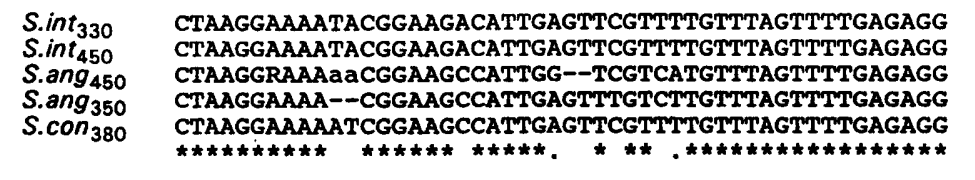

S.int 330 TCTTGT GGGGCCTTAGCTCAGCTGGGAGAGCGCCTGCTTTGCACGCAGGA S.int $_{450}$

S.ang 450

S.ang 350

S. $\operatorname{con}_{380}$

S.int $_{330}$

S.int 450

S.ang 350

S. $\operatorname{con}_{380}$

S.int 330

S.int 450

S.ang 450

S.ang 350

S. $\operatorname{con}_{380}$

$\operatorname{Sint}_{330}$

S.int 450

S.ang 450

S.ang 350

S. $\operatorname{con}_{380}$

S.int 330

S.int 450

S.ang 450

S.ang 350

S. $\operatorname{con}_{380}$

$\operatorname{S.int} 330$

S.int 450

S.ang 450

S.ang 350

S. $\operatorname{con}_{380}$

S.int 330

S.int 450

S.ang 450

S.ang 350

S. $\operatorname{con}_{380}$ TCTTGTGGGGCCTTAGCTCAGCTGGGAGAGCGCCTGCTPTGCACGCAGGA

GGTCAGCGGTTCGATCCCGCTAGGCTCCATTAGGATA--.--_.-.-GGTCAGCGGTTCGATCCCGCTAGGCTCCA ITAGGATAGAATCCTACTGAA GGTCAGCGGTTCGATCCCGCTAGGCTCCA ITAGGATAGAATCCTACTGAA GGTCAGCGGTTCGATCCCGCTAGGCTCCATTAGGATAGAATCCTACTAAA GGTCAGCGGTTCGATCCCGCTAGGCTCCANTAT-------CTAGGATG

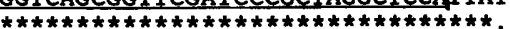

CTTAATAAAGAAGTGAAGTTGAATACGAGACTAACTTCTTAGGAAAAAAa CTTAATAAAGAAGTGAAGTTGAATACGAGACTAACTTCTTAGGAAAAAA CTTAATAAAGAAGTTAAGTTGAATACGAGACTAACT---:---:--.-CAAA--_-.--GAAATGAGATTCTTGT---TCAACTAGATAAGATAG $\star \ldots \star \star \star . \star$.

CCTTTAGTTGATGA--GATAAACTTCCTTGTGTTCATGGAACACAGCGTCAGTTTCCTATTTTTCT GATAAACTTCCTTGTGTTCATGGAACACARCGTCAGTTTYCTATTTTECT GATAG-- GTGTT-

-TATCCTAAAGT-AGCACA ACAGAAGTTTTCGCAAGCGAACCGTCTCTTTATATCCTAAAGT-AGCACA ACAGAAGTTTTCGCAAGCGAACCGTCTCTTACTATCCTAAAWTTAGCACA AAAGAAGTTGA-ACA--CGAACC-- $* * * * * * *$

TTGAAAATTGAATAACGATATCAAATAGTAACAAGAAAATAAACCGAAAA TTGAAAATTGAATAACGATATCAAATAGTAACAAGAAAATAAACCGAAAA TTGAAAATTGAATAACGATATCAAATAGTAACAAGAAAATAAACCGAAAA TTGAAAATTGAATAACGATATCAAATAGTAACAAGAAATTAAACCGAAAA TTGAAAATTGAATAACGATATCAAATAGTAACAAGAAAATAAACCGAAA-

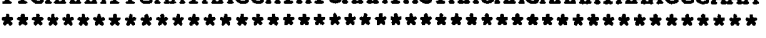

137

150

148

148 CGCTGTGAATATTAATGAGTTTATGACTGAAAGGTCAAAA-TAA CGCTGTGAATATTAATGAGTATATGACTGAGAGGTCAAAAATAA CGCTGTGAATATTAATGAGTATATGACTGAGAGGTCAAAAATAA CGCTGTGAATATTAATGAGTTTATGACTGAAAGGTCgAAAATAA

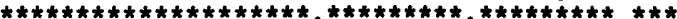

Fig. 2. Alignment of DNA sequences of 16S-23S rRNA intergenic spacers: $S$. intermedius 450 (long) [isolates HW12 (accession no. L36935) and GN556], S. intermedius $_{330}$ (short) [strain NCDO 2227 (accession no. L36934) and isolate 10a], 160 S. anginosus 450 (long) [strain NCTC 10713 250 (accession no. L36931) and isolate SL15], 247 S. anginosus 350 (short) [isolates Q4039 196 (accession no. L36932) and KR481] and S. constellatus $_{380}$ [strain NCDO 2226 (accession no. L36933) and isolate UNS55]. The tRNA Ala gene deduced by comparison with the tRNA $_{\text {Ala }}$ gene of $S$. pneumoniae (Bacot \& Reeves, 1991) is shown boxed. Positions in the alignments that are preserved in all sequences examined are indicated by *. Gaps introduced to maintain alignment are indicated by -. Differences within spacer types are: S.int ${ }_{450,}$ a at 200 is A (HW12) or (GN556); S.ang $450 . R$ at 7 is A (NCTC 10713) or G (SL15), a at 11 and 12 is A (NCTC 10713) or - (SL15), $R$ at 226 is G (NCTC 10713) or A (SL15), $Y$ at 236 is C (NCTC 10713) or $T$ (SL15), $t$ at 245 is T (NCTC 10713) or - (SL15), $W$ at 289 is T (NCTC 10713) or A (SL15); S.con $_{380} \mathrm{~g}$ at 312 is G (UNS55) or - (NCTC 2226). species (Whiley et al., 1990). That virtually all the presumptively identified, phenotypically atypical isolates tested here had spacer lengths different from those found in typical members of each of the three species suggests that they are genetically distinct. The results of DNA-DNA pairing experiments confirm this. However, the verification by DNA-DNA hybridization of sialidasenegative isolate $I 782$ as $S$. intermedius despite the production of a $380 \mathrm{bp}$ PCR band with this isolate and the presence in isolates MS101, AGP-37-W, 3206393 and FW73 of PCR products with lengths coincidental with those found in $S$. constellatus, $S$. intermedius and $S$. anginosus demonstrates that 16S-23S rRNA intergenic spacer length determination is better employed only as an adjunct to biochemical identification rather than as a substitute; the true taxonomic position of these atypical isolates and the degree of spacer length polymorphism present within other species of streptococci outside the SMG have yet to be determined.

The demonstration of the shorter (350 bp) spacer only in isolates of $S$. anginosus possessing a broader fermentation capability could be taken to suggest that these isolates constitute a separate subspecies or even species within the SMG. This evidence supports that from previous DNA-DNA hybridization experiments (Whiley \& Hardie, 1989) that included some isolates of this phenotype and which also indicated that $S$. anginosus may be a sufficiently genetically heterogeneous species to warrant further division. Clearly, the relationships between isolates currently included in $S$. anginosus requires clarification. In contrast, no phenotypic differences were detected between isolates of $S$. intermedius having long or short spacer variants.

Previous studies using DNA-DNA hybridization and $16 S$ rRNA partial sequence analysis have shown that $S$. intermedius and $S$. constellatus are more closely related to each other than to $S$. anginosus (Kilpper-Balz et al., 1984; Bentley et al., 1991). Although no formal comparisons of spacer sequences have been attempted here, visual examination of the data reveals that these relationships are not reflected by the results obtained here where the highest degree of overall spacer sequence similarity is shared 
between the long spacers of $S$. anginosus and $S$. intermedius. Interestingly, however, the highest similarity within the first 56 and last $99 \mathrm{bp}$ (i.e. omitting the highly variable central region and the tRNA $\mathrm{Ala}_{\text {gan }}$ gene is shared between $S$. intermedius and $S$. constellatus. This suggests that rearrangements in the central region are relatively recent and obscure the true ancestry of these species: one might postulate that the $450 \mathrm{bp}$ spacer is ancestral and that the 330 bp spacer type within $S$. intermedius and the 350 bp spacer type within $S$. anginosus arose by separate deletion events.

The degree of interspecies spacer heterogeneity revealed in this study, particularly between $S$. anginosus and $S$. constellatus, indicates that the same approach may be suitable for inclusion in identification schemes for other recently described species within the genus.

\section{REFERENCES}

Bacot, C. M. \& Reeves, R. H. (1991). Novel tRNA gene organization in the 16S-23S intergenic spacer of the Streptococcus pneumoniae rRNA gene cluster. J Bacteriol 173, 4234-4236.

Barry, T., Colleran, G., Glennon, M., Dunican, L. K. \& Gannon, F. (1991). The $16 \mathrm{~s} / 23 \mathrm{~s}$ ribosomal spacer region as a target for DNA probes to identify eubacteria. PCR Methods Appl 1, 51-56.

Bentley, R. W., Leigh, J. A. \& Collins, M. D. (1991). Intrageneric structure of Streptococcus based on comparative analysis of smallsubunit rRNA sequences. Int J Syst Bacteriol 41, 487-494.

Crosa, J. H., Brenner, D. J. \& Falkow, S. (1973). Use of a single strand nuclease for analysis of bacterial and plasmid deoxyribonucleic acid homo- and heteroduplexes. J Bacteriol 115, 904-911.

Frothingham, R. \& Wilson, K. H. (1994). Molecular phylogeny of the Mycobacterium avium complex demonstrates clinically meaningful divisions. J Infect Dis 169, 305-312.

Garvie, E. I. (1976). Hybridization between the deoxyribonucleic acid of some strains of heterofermentative lactic acid bacteria. Int J Syst Bacteriol 26, 116-122.

Gossling, J. (1988). Occurrence and pathogenicity of the Streptococcus milleri group. Rev Infect Dis 10, 257-285.

Gottlieb, P. \& Rudner, R. (1985). Restriction site polymorphism of ribosomal ribonucleic acid gene sets in members of the genus Bacillus. Int J Syst Bacteriol 35, 244-252.

Greisen, K., Loeffelholz, M., Purohit, A. \& Leong, D. (1994). PCR primers and probes for the 16S rRNA gene of most species of pathogenic bacteria, including bacteria found in cerebrospinal fluid. J Clin Microbiol 32, 335-351.

Gurtler, V. (1993). Typing of Clostridium difficile strains by PCRamplification of variable length 16S-23S rRNA spacer regions. $J$ Gen Microbiol 139, 3089-3097.

Hall, L. M. C. (1994). Are point mutations or DNA rearrangements responsible for the restriction fragment length polymorphisms that are used to type bacteria? Microbiology 140, 197-204.

Kilpper-Balz, R., Williams, B. L., Lutticken, R. \& Schleifer, K. H.
(1984). Relatedness of 'Streptococcus milleri' with Streptococcus anginosus and Streptococcus constellatus. Syst Appl Microbiol 5, 494-500.

Kostman, J. R., Edlind, T. D., LiPuma, J. J. \& Stull, T. I. (1992). Molecular epidemiology of Pseudomonas cepacia determined by polymerase chain reaction ribotyping. J Clin Microbiol 30, 2084-2087.

McLaughlin, G. L., Howe, D. K., Biggs, D. R., Smith, A. R., Ludwinski, P., Fox, B. C., Tripathy, N., Frasch, C. E., Wenger, J. D., Carey, R. B., Hassen-King, M. \& Vodkin, H. (1993). Amplification of rDNA loci to detect and type Neisseria meningitidis and other eubacteria. Mol Cell Probes 7, 7-17.

Morgan, E. A., Ikemura, T. \& Normura, M. (1977). Identification of spacer tRNA genes in individual ribosomal RNA transcription units of Escherichia coli. Proc Natl Acad Sci US A 74, 2710-2714.

Ruoff, K. L. \& Kunz, L. J. (1982). Identification of viridans streptococci isolated from clinical specimens. J Clin Microbiol 15, 920-925.

Stahl, D. A. \& Amann, R. (1991). Development and application of nucleic acid probes. In Modern Microbiological Methods series: Nucleic Acid Techniques in Bacterial Systematics, pp. 205-248. Edited by E. Stackebrandt \& M. Goodfellow. New York: J. Wiley.

Uemori, T., Asada, K., Kato, I. \& Harasawa, R. (1992). Amplification of the 16S-23S spacer region in rRNA operons of mycoplasmas by the polymerase chain reaction. Syst Appl Microbiol 15, 181-186.

Whiley, R. A. \& Beighton, D. (1991). Emended descriptions and recognition of Streptococcus intermedius, Streptococcus constellatus, and Streptococcus anginosus strains within the 'Streptococcus milleri group'. Int J Syst Bacteriol 41, 1-5.

Whiley, R. A. \& Hardie, J. M. (1989). DNA-DNA hybridization studies and phenotypic characteristics of strains within the 'Streptococcus milleri group'. J Gen Microbiol 135, 2623-2633.

Whiley, R. A., Fraser, H., Hardie, J. M. \& Beighton, D. (1990). Phenotypic differentiation of Streptococcus intermedius, Streptococcus constellatus, and Streptococcus anginosus strains within the 'Streptococcus milleri group'. J Clin Microbiol 28, 1497-1501.

Whiley, R. A., Beighton, D., Winstanley, T. G., Fraser, H. Y. \& Hardie, J. M. (1992). Streptococcus intermedius, Streptococcus constellatus and Streptococcus anginosus (the Streptococcus milleri group): association with different body sites and clinical infections. $J$ Clin Microbiol 30, 342-344.

Whiley, R. A., Freemantle, L., Beighton, D., Radford, A., Hardie, J. M. \& Tillotsen, G. (1993). Isolation, identification and prevalence of Streptococcus anginosus, $S$. intermedius and $S$. constellatus from the mouth. Microb Ecol Health Dis 6, 285-291.

Woese, C. R. (1987). Bacterial evolution. Microbiol Rev 51, 221-271.

Young, R. A. \& Steitz, J. A. (1978). Complementary sequences 1700 nucleotides apart form a ribonuclease III cleavage site in Escherichia coli ribosomal precursor RNA. Proc Natl Acad Sci USA 75, 3593-3597.

Young, R. A., Maklis, R. \& Steitz, J. A. (1979). Sequence of the 16S-23S spacer region in two tibosomal RNA operons of Eschericbia coli. J Biol Chem 254, 3264-3271.

Received 27 October 1994; revised 20 January 1995; accepted 26 January 1995. 